\title{
The Outline of Chinese Traditional Concept of Etiquette and Its Modern Effects
}

\author{
Hong Lian \\ School of Law, Changchun University of Science and Technology \\ \& Northeast Normal University \\ No. 7989 Weixing Road, Changchun 130022, China \\ E-mail: happylianhong@sohu.com
}

Received: March 7, 2011 Accepted: March 27, 2011 doi:10.5539/ass.v7n8p256

\begin{abstract}
Chinese traditional legal culture and legal system are self organized. The reason is that the concept of etiquette plays an immeasurable impact on the development of China's legal system. In today's China, such influences still work. They promote or suppress the process of building a modern nation ruled by law. If traditional and modern relationship cannot be correctly handled, the contemporary China will face major legislative and enforcement problems.
\end{abstract}

Keywords: Etiquette, Tradition, Influence

\section{Differences of legal implication between Chinese and Western cultures}

To correctly understand traditional Chinese culture and concept of etiquette, we should first start with the Chinese character of Fa, i.e. law. Fa in modern Chinese comes from the ancient Chinese character of "顄", which could be seen in the inscriptions of early Western Zhou. However, it means Fei (destroy) for Fa and Fei in the inscriptions of the Western Zhou are homonyms, so the two can be replaced with each other. From this we can at least be sure that Fa prior to the Spring and Autumn period does not have the connotation in the modern law. There existed Xing or penalty but not Fa or law prior to the Spring and Autumn Period and people at that time did know Xing but not Fa. The interpretation of "渥" in Shuowenjiezi, a dictionary about the explanation and study of principles of composition of character by Xu Shen in Eastern Han Dynasty, can only represent the viewpoint of Eastern Han's people. The interpretation is not the original meaning. In Shuangwenjiezi, it said that Fa meant as fair as water. Zhi, a kind of mythical animal, touching the water with its horn predicted the righteousness. It is difficult to find out when the meaning of law has changed in the existing documents. However, it is very likely that the later "law" is descendant from Fei (destroy) in connotation. Fei has another meaning of "prohibiting". Thus law gets its meaning of legal prohibition, referring to the code of prohibited behavior. Fa appeared repeatedly in the ancient documents after the Warring States period and it was inextricably linked to the prevailing political reform and concept of managing state affairs and the practice. The above analysis shows that the meaning of $\mathrm{Fa}$ in ancient Chinese is not the same as that in modern sense of "law". If such a point can not be properly understood, the concepts of traditional Chinese Fa and legal culture can not be correctly grasped. This meaning of $\mathrm{Fa}$ is accompanied with the traditional Chinese legal system and concept till the legal reform in late Qing Dynasty, which led to legal modernization in China. Just as what is said in the very beginning of Montesquieu's Spirit of Laws, translated by Yan Fu, the famous thinker and translator in modern China, there is differences in semantics between Chinese Fa and the Western "law". "It is probably in China, reason is used to tell right from wrong while prohibition in a country is called Fa. However in the Western countries, both are named law for reason and law are considered to be the same, people and things themselves are not believed to be right or wrong. This viewpoint is written down and is named law. What is written down about Chinese people's viewpoints is numerous, as is superior to the Western documents. The Western law can be translated into reason, etiquette, law and system in Chinese. Scholars can select one according to the context." That is to say, at the time Fa, semantically, referring to the prohibition of a kingdom, the code of openly prohibited behavior, was derived from Fei (destroy). In addition to this, there was reason, indicating natural and social laws, ceremony displaying social ethics, and system standing for the state administration (Guo, P2, 2006), while in the Western countries, all these can be outlined with the word of law. 


\section{The normative etiquette}

If Chinese Fa only refers to the state injunction, which tells people what to prohibit, etiquette is the normative used to positively guide the behaviors that people can do or can not do. Etiquette generates much earlier than Fa. In other words, etiquette has the feature of behavioral norm and is a kind of unique law and discipline rite.

China has been a ritual nation since the ancient times and etiquette is at the core of Chinese traditional culture. Therefore, the core of Chinese traditional legal culture is also certain to be the unique culture of etiquette, which is the essence of traditional Chinese culture. Studying traditional Chinese legal culture can not simply center around $\mathrm{Fa}$ or law, or many phenomena concerning the construction of the legal system and legal operation are unable to obtain a reasonable explanation. "Because of rituals, Chinese traditional culture began to shape a harmonious and transparent system, of which politics, law, economics, religion, science, technology and even people's daily life are part. If today's means is used to separate them from the system, we could easily find that these fields are so imperfect. They are with "defects". (Ma, P76, 2004). The ancient Chinese etiquette was an embracive system. It adjusted the relations between man and man, man and society, man and nation. The ancients had learned rituals since the childhood because rituals were the main content of family and school education. A person might not be a successful intellectual, or a prolific farmer, however, he must first be one to abide by the rituals, or his behaviors would be cast aside by the whole society or even punished by the penal law. The so-called "becoming official after excellent study" meant that he who could be good at the etiquette was able to enter the bureaucratic system to promote and popularize it to the area administered by him. The ability to effectively promote the rituals and educate the people was one of the important criteria to appraise the performance of officials. The ancients believed that rituals and Fa were a non-deviating binary system. Both were coordinated and balanced to give a code of people's behavior. Etiquette was the guiding principle of legislation. Commentaries on the Codes of Tang, the masterpiece of traditional Chinese legal culture, says "virtue and rituals are the essence of politics and education or penalty is the means adopted by politics and education". The content manifests the normative etiquette. And the content of Book of Rites was directly used in the code. Breaking the rituals would receive punishment. Minor violation of rituals would be condemned by public opinions, severe violation would be considered as a crime and would receive penalty. The coercive power of law was used to maintain the ritual norms to require the whole community to follow the etiquette. The law need not or could not be able to reach every corner of the society and the departmental laws in ancient China except the criminal law were not developed, even if the so-called perfect criminal law could not cover all the corners. However, the ancient Chinese society was able to run well for thousands of years, it can not be denied that etiquette had played a great important role.

\section{The ethical etiquette and its impact}

In a patriarchal system based on ties of blood, agricultural production went on with the family as the basic unit and the political power was distributed within the royal family on the basis of intimacy of blood relationship. Each individual was in such a network of the patriarchal family. Therefore, when etiquette adjusts the social relations, it was bound to center around the ties of relatives and the political relations based on ties of blood. The basic principle of the ceremony is "Zunzun and Qinqin or love and respect, demanding that a father is benevolent and a son is filial, brothers love each other, husband and wife, wife and aunt should live a harmonious life". (Zuo Zhuan). That is to say, every body should love his relatives, especially his respected ones such as the patriarchy authority, clan leaders, or suzerain. The elders and children must be given an order. It is a principle of patriarchal ethics reflecting the principle of male superiority with filial piety as the core, aiming at preserving the ethical and moral order within a family, family clan and patriarchy clans. The so-called Zunzun or respect means that "positions are different then the rituals are different". It requires that the subordinate, sub-suzerain, and subjects must absolutely obey and respect the corresponding superior, suzerain and lords and strictly abide by the hierarchical order. Violation of rituals is strictly prohibited. It is a principle of rank difference with "loyalty" as the core, aiming at maintaining social monarch, pariahdom, and soical hierarchy. Because of this, the traditional Chinese legal system with etiquette at the core shows the distinct ethical and hierarchical attributes.

Today, when we re-examine the etiquette, the basic feature of the traditional Chinese legal culture, we have to admit that etiquette means rituals prior to law. When the function of etiquette was re-interpreted and promoted by the Confucians, the sanctity and authority of law was not set up in Chinese society. Wise lords were good at using etiquette, paid attention to the role of moral enlightenment, and educated people by virtue. Only the oppressive monarchs resorted to the rule of law, as was the cruel manifestation, such as emperor Shihuang of Qin Dynasty. So if we examine thousands of years of traditional Chinese legal culture and system, we will find they always conceive a deep sense of human emotions. A nation of rites is also a human community. (e.g. the mutual concealment of relatives and system of delaying execution are good cases in point. The former permitted that 
relatives could conceal guilt within a range. The latter means that criminals sentenced to death or imprisonment, if his or her grandparents or parents were old without any support from other descendants, could be waived the penalty. He or she could resume the punishment after taking care of the old at home till they went to another world, as reflected the principle of love and respect and the spirit of filial piety.) In a strong humane society, the mandatory law seems to be incompatible with the strong sense of human touch. An old Chinese saying says "never deal with law when a person is alive". There are two explanations about it. On the one hand, it is because of the high cost of litigation. On the other hand, it is due to the weak legal identification. This forms sharp contrast with the legal sanctity and authority in the Western countries in the manifestation of the spirit of Western rationalism. Just as what Liang Shuming said, "Westerners have the concept of self before claiming rights to get personality development. However, since then, personal boundary is clearly defined. They are always starting to take about rights and obligations and the legal relationship. Personal independence is stressed strictly and even between married couples." (Liang, 1922, P.P.152-153). Even in the eyes of today's people, it is difficult for the ordinary Chinese people to accept because father and son, husband and wife are the most important human relations. Such ties are hard to completely separate. The selfless judge, even admired by all others, will be said to be "unreasonable". Therefore, when Western legal system is introduced into modern China on a large scale, people were surprised to find that the legal system running very well in the Western countries is unable to adapt itself to China. Failure to abide by law and to strict enforcement has occasionally appeared. Law enforcement officials themselves can not be completely divorced from the human network, which was due to the negative impacts caused by the traditional concept of etiquette.

Next, I will take the criminal law as an example to illustrate the ethical law. Ethics means the human relations. In traditional Chinese agricultural society, the most important relationship among people is the ties of blood. It has been mentioned above that ties of blood produced important influences on Chinese society and normative rituals grew based on it, and gradually rose to the field of political rule. Especially when Confucianism became the orthodox legal thinking after the Han dynasty, it is developed into three principles, that is, "ruler guides subject, father guides son, and husband guides wife". The criminal legislation after Han dynasty perfectly implemented the three principles, which makes the criminal law have the strong ethical characteristics. Ethical law emphasizes blood lineage and kinship so all violations of human relations are considered to be criminal behavior. Etiquette becomes an important criterion in determining crimes. In today's people's eyes, the etiquette has many obvious drawbacks. For instance, it clearly stipulates that not all the people are equal before the law. When a humble relative injured or killed his noble relatives, he would be severely punished while when a noble relative killed or injured his humble relatives, he would receive a light punishment or exemption from punishment, as is contrary to the modern spirit of rule with law. Thereby, most of the ethical law, after experiencing the legal reform in the late Qing Dynasty and the New Culture Movement, has been discarded, and only a part was preserved to produce some influences on the contemporary criminal law. For example, the principle of love and respect, a basic principle of rule of rite, is mentioned above. Filial piety is considered to be a basic moral concept, and unofficial behavior has always been considered a felony. Furthermore, it has a very rich content. The unofficial piety did not only refer to the shortage in material support to parents, but also included the disobedience to parents. Parents had the right of ordering or instructing their children and choosing the spouse for them. According to criminal laws from the Song Dynasty to the Qing Dynasty, parents could be free from punishment if they beat their children to death for their disobedience. Contemporary Chinese criminal law has removed those concerning the right of maintaining the patriarchy rights and has focused on promoting the Chinese traditional virtues of respecting the old and loving the young and protecting the vulnerable. But it emphasizes the material support for parents. Article 261 of the Criminal Law of the People's Republic of China stipulates that obligations must be fulfilled to support the old, the young, the sick or other people who can not live independently. Those who refuse to do it with particularly wicked nature will commit the crime of abandonment. Article 260 stipulates that he who often beats a family member living together, freezes, confines, limits freedom, abuses or forces others to labor heavily, destroys or persecutes others physically or mentally, with particularly wicked nature will commit the crime of maltreatment. Maltreatment will be handled if it is charged. These two laws do not only apply to parents and children, but also to those who have the obligations to support his family members, and only when it is with wicked nature, is it considered to be a crime. There is another example. Theft among relatives is treated differently by the traditional law according to the intimacy of relatives. The closer the ties of blood are, the lighter the penalty will be. On the contrary, the more distant the relatives are, the severer the penalty is. The purpose of legislation is to maintain harmony within the family, and family members themselves have the morality to help and support one with another. Therefore the penalty can be reduced. The contemporary China's criminal code does not make special provisions for the behavior of theft within relatives, but in a real life such cases often occur, therefore judicial interpretation is employed to specify it. That is, the theft among close 
relatives can not be considered to be a crime. Even crimes needed to be treated as crimes are different from the general thefts. This legislative intent is also to maintain harmony within the family. Furthermore, ordinarily speaking, family members live together with mutual property. Since family members can consume their common property, they have the rights to manage and control their common property. Japan's criminal law has the similar provisions. (Note 1). The contemporary China is building a country ruled by law. It is a reconstruction of the legal system, and moral law as well. The tradition of moral law has been abandoned in today's criminal law and the negative influences have emerged out of the surface, that is, the indifference of family moral values and ethical ambiguity. Human beings have the nature to love their relatives. If the legal morality in a country ruled by law violates the human nature, what the law gives to people is the fairness and the agony against the human nature. Since natural affection can not be avoided, we should take into account the spirit of modern rule of law, human nature and natural affection to reconstruct the legal ethics in Chinese society.

\section{References}

Guo, Jian. (2006). The Shadow of Haitai. Shanghai: Shanghai Joint Publishing Company.

Liang, Shuming. (1987). Eastern and Western culture and their philosophy. Commercial Press. Version of 1922.

Ma, Xiaohong. (2004). Rites and Law: Historical Connection of Law. Beijing: Peking University Press.

Zuo Zhuan. $26^{\text {th }}$ year of Zhaogong Period.

\section{Note}

Note 1. Article 244 in Japan's Criminal Law makes special stipulation about the crimes among relatives. Those who commit theft against spouse, lineal consanguinities and cohabitating relatives, is to waive punishment. Theft made against the relatives excluding the above mentioned, if it is not told, can not be presented public persecution. 